\title{
Absorption and Secretion of Water and Electrolytes by the Intact Colon in a Patient with Primary Aldosteronism*
}

\author{
R. SHIELDS, † M.D., F.R.C.S., F.R.C.S.ED. ; J. B. MILES, $\ddagger$ M.B., B.CH., F.R.C.S. \\ C. GILBERTSON,§ M.B., B.CH., M.R.C.P.
}

Brit. med. F., 1968, 1, 93-96

Potassium deficiency is a prominent feature of primary aldosteronism. The excessive losses of potassium in the urine have been well documented, but less well known and understood is the altered excretion of electrolytes in the faeces.

In a patient with primary aldosteronism Wrong et al. (1961) observed that in faecal dialysate the concentration of potassium was increased and the concentration of sodium was reduced, with a resultant decrease in the sodium: potassium ratio. These observations were confirmed in a further three patients, in one of whom the concentration of faecal electrolytes returned to normal after the removal of an adrenal adenoma (Wrong and Metcalfe-Gibson, 1965). It is likely, but by no means established, that these alterations in the ionic composition of the faeces in primary aldosteronism were brought about by the action of aldosterone on the intestinal handling of electrolytes.

Experiments in animals and several indirect studies in man have suggested that adrenal mineralocorticoids enhance the absorption of sodium and the secretion of potassium by the intestine (for review, see Shields, 1964, 1966a). Only recently, however, has it been possible to study directly the absorptive ability of the colon in conscious patients. In two patients with a segment of transverse colon isolated for several weeks from the rest of the gastrointestinal tract we (Shields et al., 1966) have shown that potassium was secreted more rapidly by the colon when aldosterone was infused intravenously. Using the technique of colonic intubation and perfusion (Levitan et al., 1962), Levitan and Ingelfinger (1965) and Levitan (1967) found that the colonic absorption of sodium was increased by aldosterone and $9 \alpha$-fluorohydrocortisone (fludrocortisone).

We have developed the technique of Levitan et al. (1962) to allow the simultaneous measurement of the rates at which not only water but also sodium and potassium are exchanged in both directions across the colonic mucosa (Shields and Miles, 1965b ; Shields, 1966b).

In this paper we report a study of the net transport and unidirectional fluxes of sodium, potassium, and water by the intact colon of a patient with primary aldosteronism before and after the removal of a tumour of the adrenal cortex.

\section{The Patient}

At a routine examination for life assurance in 1959 the patient, who had no symptoms, was found to have an elevated blood pressure $(200 / 100 \mathrm{~mm}$. $\mathrm{Hg})$. In 1963 he began to experience undue breathlessness on exertion and noticed that he passed more urine at night than during the day. The following year he suffered cramping pains in his limbs, which seemed to be rather weak. He was habitually costive but did not take purgatives; his stool was of normal colour and consistency. He had not received digitalis or its analogues.

- A preliminary communication of this paper was given to the Surgical Research Society (Shields and Miles, 1965a)

t Senior Lecturer and Consultant Surgeon, Royal Infirmary, Cardiff.

₹ Research Assistant in Surgery, Royal Infirmary, Cardiff. Present appointment: Senior Registrar in Neurosurgery, United Birmingham Hosputals.

S Senior Registrar in Medicine, Royal Infirmary, Cardiff. Present appointment: Consultant Physician, St. James Hospital, Tredegar, Monmouthshire.
On clinical examination he was seen to be a healthy-looking man of 58 without any external evidence of endocrinopathy. His elevated blood pressure was confirmed. The heart was not enlarged, but in the optic fundi moderate hypertensive changes were observed. The electrocardiogram showed a marked depression of the $S-T$ segment.

\section{Investigations}

(1) Fluid and Electrolyte Metabolism.-The concentration of potassium in the serum was $1.8 \mathrm{mEq} / \mathrm{litre}$, and that of sodium $149 \mathrm{mEq} / \mathrm{l}$. With a daily diet containing $150 \mathrm{mEq}$ of potassium and $100 \mathrm{mEq}$ of sodium the serum potassium rose to $3.0 \mathrm{mEg} / 1$. but then fell to $2.4 \mathrm{mEq} / \mathrm{l}$. When a similar diet, but providing less than $10 \mathrm{mEq}$ of sodium in 24 hours, was given, the serum potassium rose to $4.2 \mathrm{mEq} / \mathrm{l}$., the daily output of potassium in the urine fell from 50 to $10 \mathrm{mEq} / 24$ hours, and the urinary sodium from 100 to $14 \mathrm{mEq} / 24$ hours. On a diet providin $\mathrm{g} 20 \mathrm{mEg}$ of potassium daily, the loss of potassium in the urine remained at about $40 \mathrm{mEq} / 24$ hours. The mean daily loss of potassium in faeces collected over three days was $25 \mathrm{mEq}$ the normal range with the method of Crawford and Brooke (1957) is $5-10 \mathrm{mEq} /$ 24 hours). The mean daily faecal excretion of sodium was $3.5 \mathrm{mEg}$ (normal range 1-8 mEq/24 hours). The diurnal rhythm of potassium excretion in the urine was reversed: the maximum excretion occurred at night, compared with a maximum excretion at noon in control subjects (Elmslie et al., 1964). The plasma volume, determined by isotope dilution with radioiodinated human serum albumin, was $3,900 \mathrm{ml}$., the value for a healthy male patient of similar height and weight being $2,900 \mathrm{ml}$. (Nadler et al., 1962). The serum calcium was $5.1 \mathrm{mEq} / 1$.

(2) Acid-base Status.-Examination of a sample of arterial blood by the micro-Astrup technique (Astrup et al., 1960) showed nonrespiratory alkalosis- $p \mathrm{H} 7.54, \mathrm{PCO}_{2} 48 \mathrm{~mm}$. $\mathrm{Hg}$, and standard bicarbonate $38 \mathrm{mEq} / \mathrm{l}$.

(3) Steroid Investigations (Dr. J. K. Grant).-In urine, collected over four days, the mean excretion rate of 17-oxysteroids (Medical Research Council, 1963 ; James and Caie, 1964) was 12 mg./ 24 hours (normal range for this age and sex: 4-15 mg./24 hours), and of 17-hydroxycorticosteroids (Few, 1961) $17 \mathrm{mg} . / 24$ hours (normal range: $4.5-18.5 \mathrm{mg} . / 24$ hours). Though the urinary excretion rate of aldosterone was within the normal range $(6.8 \mu \mathrm{g}$./ 24 hours (Brooks, 1960)), the rate of its secretion measured on two separate occasions, with tritiated aldosterone $3.0 \mu \mathrm{Ci}\left(1,2-{ }^{3} \mathrm{H}\right.$ aldosterone) was greatly increased, being $524 \mu \mathrm{g}$. initially and on a subsequent occasion $2.4,3.4$, and $2.6 \mathrm{mg} . / 24$ hours (normal $25-500 \mu \mathrm{g} . / 24$ hours). The rates of secretion of cortisol and corticosterone (with $0.5 \mu \mathrm{Ci} 4-{ }^{14} \mathrm{C}$-cortisol and $1 \mu \mathrm{Ci} 1,2-{ }^{3} \mathrm{H}$ corticosterone (Cope and Black, 1958) were, respectively, 26.4 and $11.3 \mathrm{mg} . / 24$ hours, the latter rate being above the normal range of $1.3-4$ mg. $/ 24$ hours.

(4) Renal Investigations.-The measurement of the diurnal output of urine over 72 hours showed that $1,300 \mathrm{ml}$. was excreted at nigh (6 p.m. to 6 a.m.), and $600 \mathrm{ml}$. during the day. The reaction of the urine, usually $p H 7$, fell to $p H 5.8$ after an acid load (ammonium chloride, $0.1 \mathrm{~g} . / \mathrm{kg}$. body weight). There was a trace of albumin in the urine, microscopical examination of which did not show any abnormality. The blood urea was $50 \mathrm{mg} . / 100 \mathrm{ml}$.; serum and urine osmolalities were respectively 303 and $530 \mathrm{Osm} / \mathrm{kg}$. water.

(5) Radiological Investigations (Dr. R. G. Pitman).-Intravenous pyelography, perirenal insufflation with oxygen, and aortography did not reveal any abnormality. The appearances of an $x$-ray film of the chest were within normal limits. 


\section{Operation}

The operation was performed by Professor A. P. M. Forrest. The adrenal glands were approached through the abdomen. A discrete mass, diameter $2.5 \mathrm{~cm}$., was easily palpated in the right adrenal gland. Both the gland and its contained tumour were removed. The left adrenal gland was rather dark in appearance and had a number of small purplish specks scattered over its surface. A biopsy was taken from the right kidney.

\section{Pathology}

Right Adrenal Gland (Professor T. Symington).-The specimen, which weighed 9.8 g., contained a well-encapsulated yellow-orange tumour composed predominantly of cells similar morphologically to those of the zona fasciculata of the normal adrenal cortex. They were filled with lipid and showed little pleomorphism. The nuclei were small and dense. Mitoses were inconspicuous. A few islands were noted in which the cells of the tumour bore a distinct morphological resemblance to zona glomerulosa, and there were occasional foci with tumour cells similar to the compact cells of the zona reticularis. The last two types of cells composed only a few areas of the lesion. The entire tumour was divided into alveoli of varying sizes by prominent fibrovascular trabeculae derived from a wellformed capsule. The associated normal adrenal gland showed focal lipid depletion consistent with the reaction to stress. The zona glomerulosa was focally hyperplastic and projected as tongue-like areas into the substance of the normal cortex to varying depths, some almost reaching the zona reticularis. The arteries and arterioles within the tumour and in its capsule showed prominent hypertensive changes. The appearances of the growth were those of a benign tumour associated with primary aldosteronism. There was focal hycerplasia of the zona glomerulosa of the attached gland and a similar focal hyperplasia in the biopsy of the contralateral adrenal gland.

Renal Biopsy (Dr. W. Jones Williams).-The features were those of non-specific chronic pyelonephritis with benign hypertension.

\section{Subsequent Progress}

Apart from a small pulmonary infarct on the fourteenth day after operation, the postoperative course was uneventful.

The patient remained well and free of symptoms. His arterial blood pressure was still high $(190 / 100 \mathrm{~mm}$. $\mathrm{Hg})$ but the serum potassium remained within normal limits $(4.2 \mathrm{mEq} / \mathrm{litre})$ without medication or potassium supplements.

\section{Control Subjects}

The control subjects were eight adult males aged 20-65 years. Four were medical students and the rest otherwise healthy patients admitted for the operative repair of inguinal hernia. Permission was obtained from the patients and from the control subjects according to the proposals laid down by the Medical Research Council (1964).

\section{Measurement of Rates of Colonic Transport of Sodium, Potassium, and Water}

In the patient the transport of sodium, potassium, and water across the colonic mucosa was studied one week before and three months after the removal of the tumour in the right adrenal cortex. The preoperative studies were performed after correction of the potassium deficiency. For six days preceding the absorption studies, however, the patient was on the usual ward diet containing $150 \mathrm{mEq}$ of sodium and $75 \mathrm{mEq}$ of potassium per 24 hours and was not receiving any potassium supplements or other medication.

When investigation of the colon was repeated three months after the removal of the adrenocortical tumour the patient was well, was eating an unrestricted diet, and did not display any evidence of potassium deficiency. The control subjects were eating an unrestricted diet (containing plenty of salt) until 12 hours before the absorption studies.

The details of the method have already been described (Shields, 1966b). Briefly, the patient and the volunteers swallowed a long polyvinyl tube, until the tip of the tube lay in the caecum.

All subjects were fasted for 12 hours before colonic perfusion. A study was begun by washing the colonic lumen with Tyrode's solution, introduced through the oral tube and collected at the anus through a wide-bore tube which had been inserted into the rectum until its tip lay $10 \mathrm{~cm}$. from the anal margin. Preliminary washing was continued until the effluent from the rectal tube was free of faeces and other solid material; usually one to two hours were required.

After an interval of two hours, test solution was perfused through the colon at $25 \mathrm{ml}$./minute by a constant infusion pump. The effluent from the rectal tube was collected in 10-minute periods. Usually 1 to 2 litres of test solution were perfused for 60 to 90 minutes. The specimens collected during the first 20 to 30 minutes of perfusion were discarded.

The test solution was freshly prepared, modified Tyrode's solution (Code and McIntire, 1956) containing ${ }^{24} \mathrm{Na}(2 \mu \mathrm{Ci} / 1$. solution), ${ }^{42} \mathrm{~K}(4 \mu \mathrm{Ci} / 1$. solution), deuterium oxide $(1 \% \mathrm{v} / \mathrm{v})$, and, as a non-absorbed marker, poylethylene glycol of molecular weight $4,000(1 \% \mathrm{w} / \mathrm{v})$.

The activities of radioactive sodium and potassium in the test solution and in the aliquots of the effluent were determined by simultaneous counting in a Geiger-Müller liquid counter and in a thallium-activated sodium iodide scintillation counter (Veall and Vetter, 1958 ; Shields et al., 1966). The chemical concentrations of sodium and potassium were determined by flame photometry, and the concentration of deuterium oxide in an infrared spectrometer (Perkin-Elmer 337) by a modification (Shields et al., 1966) of the method of Berglund-Larsson (1956). The concentrations of polyethylene glycol were estimated by the method of Hydén (1955). The errors of the various determinations have been given in detail (Shields et al., 1966).

Terminology.-Sodium, potassium, and water are simultaneously exchanged in both directions across the colonic mucosa ; for each substance the difference between the rates of unidirectional movement is referred to as its net transport. The term "absorption" is restricted to net transport where more of the substance leaves the intestinal lumen and enters the body than moves in the opposite direction; by convention the rate of absorption is preceded by a plus sign. When the substance enters the intestinal lumen more rapidly than it leaves, net transport is referred to as secretion, whose rate is preceded by a minus sign.

Calculations. - The rates of net transport were calculated from the formulae proposed by Levitan et al. (1962). The rates of unidirectional movement of sodium, potassium, and water were calculated with the use of previously described formulae (Shields, 1966b).

\section{Results}

\section{Rates of Intestinal Transport}

Net Transport.-From the mean rates of net transport of sodium, potassium, and water calculated from 27 test periods in eight control subjects it is evident that the normal human colon absorbed sodium and water and secreted potassium under the conditions of this study. In the patient with primary aldosteronism the rates of potassium secretion into the colonic lumen were considerably increased before operation and returned to within the range of the control subjects three months after the removal of the tumour (Table I). The rates of absorption of sodium and water before and after the operation were within the range observed in control subjects. 
TABLE I.-Rates of Movement of Sodium, Potassium, and Water Across the Mucosa of Intact Colon in Patient with Primary Aldosteronism Before and After Removal of Tumour, Compared with those in Eight Control Subjects

\begin{tabular}{|c|c|c|c|c|c|c|c|c|c|}
\hline & \multicolumn{3}{|c|}{ Sodium (mEq./min.) } & \multicolumn{3}{|c|}{ Potassium (mEq./min.) } & \multicolumn{3}{|c|}{ Water (ml./min.) } \\
\hline & Net & Out of Lumen & Into Lumen & Net & Out of Lumen & Into Lumen & Net & Out of Lumen & Into Lumen \\
\hline $\begin{array}{l}\text { Patient: } \\
\text { Before operation }\end{array}$ & $\begin{array}{l}+0.46 \\
+0.50 \\
+0.17 \\
+0.13\end{array}$ & $\begin{array}{l}0.75 \\
0.70 \\
1.27 \\
0.53\end{array}$ & $\begin{array}{l}0 \cdot 29 \\
0 \cdot 20 \\
1 \cdot 10 \\
0 \cdot 40\end{array}$ & $\begin{array}{l}-0.137 \\
-0.164 \\
-0.111 \\
-0.050\end{array}$ & $\begin{array}{l}0.021 \\
0.014 \\
0.025 \\
0.011\end{array}$ & $\begin{array}{l}0.158 \\
0.178 \\
0.136 \\
0.061\end{array}$ & $\begin{array}{l}+1.7 \\
+2.2 \\
+1.1 \\
+0.1\end{array}$ & $\bar{z}$ & $\bar{z}$ \\
\hline After operation \{ & $\begin{array}{l}+0.30 \\
+0.56 \\
+0.79\end{array}$ & $\begin{array}{l}0.90 \\
0.80 \\
1.08\end{array}$ & $\begin{array}{l}0 \cdot 60 \\
0 \cdot 24 \\
0 \cdot 29\end{array}$ & $\begin{array}{l}-0.020 \\
-0.006 \\
-0.005\end{array}$ & $\begin{array}{l}0.013 \\
0.018 \\
0.026\end{array}$ & $\begin{array}{l}0.033 \\
0.024 \\
0.031\end{array}$ & $\begin{array}{l}+0.3 \\
+1.8 \\
+4.7\end{array}$ & $\begin{array}{l}21 \cdot 3 \\
22 \cdot 0 \\
27 \cdot 5\end{array}$ & $\begin{array}{l}20.0 \\
21.8 \\
22 \cdot 8\end{array}$ \\
\hline $\begin{array}{l}\text { Controls (8): } \\
\text { Mean } \\
\text { Standard deviation }\end{array}$ & $\begin{array}{r}0.39 \\
0.20\end{array}$ & $\begin{array}{l}0.68 \\
0.16\end{array}$ & $\begin{array}{l}0.31 \\
0.16\end{array}$ & $\begin{array}{r}-0.024 \\
0.012\end{array}$ & $\begin{array}{l}0.017 \\
0.005\end{array}$ & $\begin{array}{l}0.041 \\
0.013\end{array}$ & $\begin{array}{l}+1 \cdot 9 \\
1 \cdot 2\end{array}$ & $\begin{array}{r}21.5 \\
3.4\end{array}$ & $\begin{array}{r}19.6 \\
4.3\end{array}$ \\
\hline
\end{tabular}

Unidirectional Fluxes.-In the patient before operation potassium moved into colonic lumen at a significantly greater rate than in the control subjects. After operation the rate of movement of potassium in this direction returned to within the range observed in the control subjects (Table I). The rates of unidirectional flux of sodium before and after operation, and those of water after operation, were within the range of those determined in control subjects.

\section{Concentration of Electrolytes in the Perfused Test Solution}

When the test solution was perfused through the colon of control subjects there was a slight but significant decrease in the concentration of sodium and a small but significant increase in the concentration of potassium. In the patient before operation the concentration of potassium was increased twofold and threefold. After operation the increase in the concentration of potassium was no greater than that found in the control subjects (Table II).

TABLE II.-Changes in Concentration of Electrolytes in Perfusion Solution in Patient with Primary Aldosteronism Before and After Removal of Tumour, Compared with Those in Eight Control Subjects

\begin{tabular}{|c|c|c|c|}
\hline Subject & Solution & $\begin{array}{l}\text { Potassium } \\
(\mathrm{mEg} / \mathrm{l} .)\end{array}$ & $\begin{array}{c}\text { Sodium } \\
\text { (mEq./1.) }\end{array}$ \\
\hline Patient: & Infused solution & $3 \cdot 8$ & 152 \\
\hline \multirow[t]{2}{*}{ Before operation } & Rectal perfusate & $\begin{array}{r}10 \cdot 5 \\
11.0 \\
9.9 \\
8.0\end{array}$ & $\begin{array}{l}157 \\
147 \\
152 \\
142\end{array}$ \\
\hline & Infused solution & $4 \cdot 0$ & 146 \\
\hline \multirow[t]{2}{*}{ After operation } & Rectal perfusate \{ & $\begin{array}{l}5 \cdot 5 \\
4 \cdot 8 \\
4 \cdot 7 \\
4 \cdot 8\end{array}$ & $\begin{array}{l}140 \\
137 \\
140 \\
136\end{array}$ \\
\hline & $\begin{array}{l}\text { (mean } \pm \text { S.E.) } \\
\text { Rectal perfusate }\end{array}$ & $\begin{array}{l}4 \cdot 2 \pm 0 \cdot 1 \\
5 \cdot 5 \pm 0 \cdot 2\end{array}$ & $\begin{array}{l}156 \pm 1 \cdot 2 \\
147 \pm 2 \cdot 2\end{array}$ \\
\hline Control subjects (8) & $\begin{array}{l}\text { Mean difterence } \\
t_{\mathrm{P}}^{ \pm S . E . ~ o f ~ m e a n ~}\end{array}$ & $\begin{array}{c}1.3 \pm 0.2 \\
6.0 \\
<0.001\end{array}$ & $\begin{array}{c}9 \pm 2.5 \\
3.4 \\
<0.01\end{array}$ \\
\hline
\end{tabular}

No alteration in the concentration of sodium in the perfused solution was observed in the patient before or after operation.

\section{Discussion}

The case described in this report presented most of the clinical and biochemical features of primary aldosteronism, a diagnosis which was subsequently confirmed by the removal of a histologically typical tumour of the adrenal cortex (Neville and Symington, 1966). In the patient the striking abnormality in the colonic handling of water and electrolytes was a marked enhancement of the movement of potassium into the lumen-at a rate of four to five times that observed in control subjects. As a result the daily faecal loss of potassium was greatly increased and the concentration of potassium in an isotonic solution perfused through the colon was more than doubled. With the removal of the tumour the secretion of potassium by the colon returned to normal.

Similar changes in the colonic transport of potassium have been observed both in man and in the dog during the intravenous infusion of aldosterone (Shields et al., 1966). Moreover, the intestinal action of aldosterone could be blocked in the dog by the previous administration of spironolactone (Elmslie et al., 1966). Also, in dogs, the colonic secretion of potassium was increased by deoxycortone (Berger et al., 1960) and during salt depletion (Clarke et al., 1967). There seems good evidence, then, confirmed by the present study, that adrenal mineralocorticoids act on the colon to augment its secretion of potassium.

On the other hand, Levitan and Ingelfinger (1965) and Levitan (1967), using a technique similar to the one described in this paper, did not find any change in potassium secretion by the colon when aldosterone and fludrocortisone were given to healthy subjects. Two explanations may be advanced to explain this difference. Firstly, Levitan and Ingelfinger (1965) injected $1 \mathrm{mg}$. of aldosterone rapidly. We (Shields et al., 1966) have noted that the effect of a single rapid injection of aldosterone on potassium secretion was slight and transient and that marked increase in the movement of potassium into the colonic lumen occurred only when aldosterone was given by continuous infusion, even though the total dose did not exceed $300 \mu \mathrm{g}$. Secondly, as Levitan (1967) pointed out, the test solution which they had used was not ideal for evaluating potassium secretion.

The absence of any change in the colonic absorption of sodium in primary aldosteronism is noteworthy and requires comment. Patients with primary aldosteronism usually become adapted to the renal sodium-retaining activity of aldosterone, a response probably related to the "escape" from sodium retention during the prolonged administration of aldosterone (August et al., 1958). A similar adaptation to the action of aldosterone on the absorption of sodium by the colon may be postulated. That this explanation is not entirely satisfactory is suggested by previous reports of low concentration of sodium in faeces and faecal dialysates in primary aldosteronism (Milne et al., 1957 ; Wrong and Metcalfe-Gibson, 1965).

However, the daily excretion of sodium in the faeces is low -from about 3 to $10 \mathrm{mEq} /$ day. Consequently further reduction in the faecal loss of sodium because of increased colonic absorption will barely disturb electrolyte homoeostasis. In contrast, the enhanced colonic secretion of potassium in response to aldosterone and the subsequent loss of this ion in increasing amounts in the faeces can be of clinical importance. In health, the faecal excretion of potassium represents $20 \%$ of the total loss of potassium from the body by all routes. Though the urinary loss of potassium is greatly increased in aldosteronism and during corticosteroid therapy, the faecal excretion of potassium may also be increased and the extent of potassium deficiency may be seriously underestimated if only the electrolyte content of the urine is measured. Thus, for example, in 
the present patient the daily output of potassium in the faeces represented one-half of the total sensible loss of potassium from the body.

\section{Summary}

In a patient with primary hyperaldosteronism the rates of net transport and of unidirectional fluxes of sodium, potassium, and water in the intact colon were measured before and after removal of the adrenocortical tumour, by perfusing the colon with an isotopically labelled test solution introduced into the caecum through a tube passed by mouth. The results in this patient were compared with those in eight control subjects. Before removal of the aldosterone-producing tumour the colon of the patient secreted potassium at four to five times the rate in control subjects. The unidirectional flux of potassium into the colonic lumen was greatly enhanced and the daily loss of potassium in the faeces increased. The rates of potassium transport returned to within the range observed in control subjects after the removal of the tumour.

We are indebted to Dr. William Phillips and Professor A. P. M. Forrest, who allowed us to examine the patient under their care ; to Professor T. Symington and Dr. J. K. Grant, of the Royal Infirmary, Glasgow, and to Drs. W. Jones Williams and R. G. Pitman, of the United Cardiff Hospitals, for permission to quote from their histological, biochemical, and radiological reports. We are grateful to the patient and the control subjects for their consent and co-operation in this study. We acknowledge the technical assistance of Mr. H. Kincaid and Miss Margaret Davies. This work was supported by a grant from the Medical Research Council.
REFERENCES

Astrup, P., Jørgensen, K., Andersen, O. S., and Engel, K. (1960). Lancet, 1,1035 .

August, J. T., Nelson, D. H., and Thorn, G. W. (1958). F. clin. Invest., 37. 1549.

151, 352 .

Berglund-Larsson, U. (1956). Acta chem. scand.,
Brooks, R. V. (1960). Mem. Soc. Endocr., 8, 9.

Clarke, A. M., Miller, M., and Shields, R.'(1967). Gastroenterology, 52 , 846.

Code, C. F., and McIntire, F. C. (1956). Meth. biochem. Anal., 3, 49. Cope, C. L., and Black, E. G. (1958). Clin. Sci., 17, 147.

Crawford, N., and Brooke, B. N. (1957). Lancet, 1, 864.

Elmslie, R. G., Mulholland, A. T., and Shields, R. (1964). Ann. Surg., 159, 377.

Few, J. D. (1961). (1966). Gut, 7, 697.

Hydén, S. (1955). K. LantbrḦogsk. Annlr., 22, 139.

James, V. H. T., and Caie, E. (1964). A. clin. Endocr., 24, 180

Levitan, R (1967). 3. Lab. clin. Med., 69, 558 .

Forduran, J. S., Burrows, B. A., and Ingelfinger, F. J. (1962). clin. Invest., 41, 1754 .

and Ingelfinger, F. J. (1965). Ibid., 44, 801.

Medical Research Council (1963). Lancet, 1,1415

(1964). Report for the year 1962-3 to Committee of Privy Council. p. 21 H.M.S.O., London.

Milne, M. D., Muebrcke, R. C., and Aird, I. (1957). Quart. 7. Med., 26. 317 .

Nadler, S. B., Hidalgo, J. U., and Bloch, T. (1962). Surgery, 51, 224

Neville, A. M., and Symington, T. (1966). Cancer, 19, 1854.

Shields, R. (1964). Monographs in Surgical Sciences, 1, 119.

- (1966a). In Proceedings of a Conference on Postgraduate Gastroenterology, edited by T. J. Thomson and I. E. Gillespie, p. 30. London.

(1966b). Brit. 7. Surg., 53, 893.

and Miles, J. B. (1965a). Ibid., 52, 68.

(1965b). Postgrad. med. F., 41, 435

Mulholland, A. T., and Elmslie, R. G. (1966). Gut, 7, 686

Veall, N., and Vetter, H. (1958). Radioisotope Techniques in Clinical Research and Diagnosis. London.

Wrons, O., and Metcalfe-Gibson, A. (1965). Proc. roy. Soc. Med., 58 1007 .

Morrison, R. B., and Hurst, P. E. (1961). Lancet, 1, 1208.

\section{Preliminary Communications}

\section{Direct Evidence for Presence of $\mathbf{P h}^{\prime}$ Chromosome in Erythroid Cells}

Brit. med. F., 1968, 1, 96-98

Strong but indirect evidence (Tough et al., 1963 ; Truillo and Ohno, 1963 ; Whang et al., 1963) has suggested that in chronic granulocytic leukaemia erythroid as well as myeloid precursors contain the $\mathrm{Ph}^{1}$ chromosome. Whang et al. (1963), for instance, found a $90-100 \%$ incidence of the $\mathrm{Ph}^{1}$ chromosome in bone marrow cells of 13 patients in drug-induced clinical remission known to have a moderately high proportion of dividing normoblasts. Recently, Clein and Flemans (1966) obtained more direct evidence by combining standard cytogenetic techniques with Perls's Prussian blue stain for iron. They demonstrated siderotic granules in the cytoplasm surrounding some $\mathrm{Ph}^{\prime}$-positive metaphase plates derived from a patient with blastic crisis of chronic granulocytic leukaemia in whose marrow a prominent sideroblastic element was also present.

To obtain further direct evidence for the occurrence of the $\mathrm{Ph}^{1}$ chromosome in erythroblasts, a bone marrow aspirate from a patient with chronic granulocytic leukaemia in drug-induced clinical remission was cultured with ${ }^{59} \mathrm{Fe}$ and ${ }^{55} \mathrm{Fe}$ (Suit et al., 1957) and the $\mathrm{Ph}^{1}$ chromosome was found in all erythroid metaphase plates examined.

\section{Materials AND Methods}

The patient was a 56-year-old man who presented with chronic granulocytic leukaemia in January 1967. He was subsequently treated with busulphan, and was in good clinical remission at the time of this study in July 1967, when a sternal bone marrow aspirate contained 178 normoblasts per 1,000 nucleated cells as determined by May-Grünwald-Giemsa staining.

Materials.-The culture medium consisted of $12 \mathrm{ml}$. of Medium 199, an additional $0.1 \mathrm{ml}$. of Solution D-G-P for Medium 199 (Commonwealth Serum Laboratories, Melbourne); $0.01 \mathrm{ml}$. of heparin, $0.02 \mu \mathrm{g}$. of demecolcine, and $8 \mathrm{ml}$. of $\mathrm{AB}$ serum. The isotopes used were ${ }^{59} \mathrm{Fe}$ and ${ }^{55} \mathrm{Fe}$, obtained as ferric chloride in $0.01 \mathrm{~N} \mathrm{HCl}$ from the Radiochemical Centre, Amersham. Kodak AR-10 stripping film was used for the autoradiography.

Methods.-The bone marrow aspirate was added to the culture medium and the resulting cell suspension divided into $10-\mathrm{ml}$. aliquots, to which were added $200 \mu \mathrm{Ci}$ of ${ }^{59} \mathrm{Fe}$ or $200 \mu \mathrm{Ci}$ of ${ }^{55} \mathrm{Fe}$. Cultures were incubated at $37^{\circ} \mathrm{C}$. for 12 hours, which was found to be the optimal time for the uptake of isotope by actively dividing normoblasts. Both samples were then treated as follows. The cells were washed with Hanks's saline, and smears made to determine ${ }^{59} \mathrm{Fe}$ and ${ }^{55} \mathrm{Fe}$ uptake by the normoblasts. The remainder of each sample was then incubated for 10 minutes at $37^{\circ} \mathrm{C}$. with $0.075 \mathrm{M} \mathrm{KCl}$ hypotonic solution, after which the cells were fixed with a freshly prepared formaldehyde-acetic-acid-methanol fixative for 10 minutes. They were then resuspended in fresh fixative and chromosome preparations were made immediately by the "flaming" technique.

Autoradiograms of the smear and chromosome preparations were exposed for 21 days at $4^{\circ} \mathrm{C}$., and developed for five minutes at $20^{\circ} \mathrm{C}$. with Kodak D-19 developer. The smears were stained with May-Grünwald-Giemsa, and the chromo- 